\title{
EDUCAÇÃO AMBIENTAL EM PAU DOS FERROS (RN): EM FOCO A ESCOLA MUNICIPAL PROFESSOR SEVERINO BEZERRA
}

Maria Leidiana Lira de Sousa ${ }^{1}$

Argeu Cavalcante Fernandes ${ }^{2}$

Resumo: Esta pesquisa refere-se a um estudo de caso, com observação participante, e teve como objetivo diagnosticar a situação da Educação Ambiental na Escola Municipal Severino Bezerra, no município de Pau dos Ferros-RN. Deteve-se ao acompanhamento das turmas de $8^{\circ}$ e $9^{\circ}$ anos, com o intuito de mostrar como a escola inclui a questão ambiental no cotidiano e em sua grade curricular. Com esta pesquisa, averiguamos que a instituição escolar tem se esforçado para que a Educação Ambiental perpasse por todas as áreas de ensino, embora encontre alguns desafios para sua efetivação. Um exemplo disso é o fato de apenas as disciplinas de Ciências e Geografia inserirem a temática em seus planos de aula, e darem continuidade ao estudo das questões ambientais no decorrer do ano letivo. Através da interpretação dos resultados da pesquisa, pretendemos incitar a discussão sobre a Educação Ambiental nas séries finais do ensino fundamental, viabilizando sua inclusão como eixo temático às demais áreas de ensino.

Palavras-chave: Educação Ambiental; Transversalidade; Interdisciplinaridade.

${ }^{1}$ Graduada em Pedagogia Campus Avançado Maria Elisa de Albuquerque Maia.

E-mail: ageldcavalcanti@hotmail.com.

${ }^{2}$ Mestrando em Ensino de Ciências Exatas e Ambientais pela UERN.

E-mail: ageldcavalcanti@hotmail.com.

Revbea, São Paulo, V 10, N²: 318-343, 2015. 


\section{Introdução}

Nos dias atuais, tem-se observado uma maior preocupação com a situação de degradação do meio ambiente por parte dos estudiosos, meios de comunicação e a população em geral. É sabido que se não houver uma sensibilização por parte da população, no que diz respeito ao uso indevido dos recursos naturais, a longo prazo terão notícias nada animadoras sobre os desastres ambientais que deverão afetar os setores políticos, econômicos, sociais e culturais em nível nacional e principalmente regional. Sendo que, em algumas localidades/regiões menos favorecidas economicamente, os abalos serão ainda mais sentidos. Por isso, falar de Educação Ambiental, doravante (EA) não é tarefa fácil, tão pouco pô-la em prática.

Espera-se das escolas mais iniciativas com relação à divulgação de hábitos sustentáveis, e um acompanhamento permanente ao longo do ano letivo, algo que realmente faça o diferencial, e não apenas mobilize a classe escolar em determinadas datas comemorativas ou em realizações de projetos semestrais. Serão necessárias ações que viabilizem a adoção de boas práticas no cotidiano dos alunos, para que os mesmos possam levar os ensinamentos para além dos muros da escola, para a sua vida pessoal, para a de parentes e da comunidade em geral.

Em resposta as reivindicações por qualidade de vida e as discussões sobre a temática em questão, é de suma importância para o progresso e a repercussão das ações de algumas escolas onde a EA já é uma realidade, pois nessas instituições, os educadores e equipe pedagógica que estão à frente do ensino, em sua maioria, estão interessados e preocupados com a situação da degradação da natureza e se empenham sinceramente para amenizá-la.

Porém, as práticas resultantes de seu empenho, normalmente são ineficazes para atuar de forma indicativa no processo de alteração da realidade. No entanto, alguns professores não estão totalmente envolvidos e/ou comprometidos com as causas naturais e sociais de preservação do meio ambiente, pois, segundo estes, as escolas não dispõem de recursos metodológicos adequados, o que lhes gera desânimo frente às questões ambientais.

Nessa perspectiva, fica evidente a necessidade do estudo de Educação Ambiental por toda a população e em especial no âmbito escolar, pois é na escola onde se encontra esperança de êxito na busca por mudança e a mesma tem papel relevante nessa busca, por ser um dos lugares mais propícios à disseminação da $E A$, e onde as interações acontecem, sejam com os funcionários, com os alunos, pais de alunos, professores e comunidade em geral.

As instituições de ensino devem primar por estarem sempre no meio do caminho, tentando uma ação que incite mudanças de comportamento e valores. Primando por uma atuação concreta, que não as coloque em situação 
de meros reprodutores no segmento de construção de uma sociedade. Não apenas criar novos métodos e procedimentos, porém renovar em sentido literal as práticas atuais, na busca de uma reflexão crítica e uma ação criativa, no que concerne a disseminar soluções possíveis para amenizar a situação de degradação ambiental.

Dessa forma, faz-se necessário a inclusão da questão ambiental no dia a dia, nos planos de aula escolares, para que se efetive sua característica transversal e interdisciplinar. Que o ato de educar, esteja pautado no desejo de edificar uma sociedade que anseie uma vida nova, na qual, os valores se baseiem na sustentabilidade, em que o ambiente do qual estão inseridos não venha sucumbir por negligência, e que o uso sustentável seja fator primordial nessa cadeia de mudanças. Sendo assim, quando se enfatiza a EA, busca-se propor novos padrões de comportamento, valores e conceitos à sociedade contemporânea.

Tendo em vista a relevância de se discutir e abordar a temática, no que diz respeito à forma de se trabalhar a Educação Ambiental, optou-se por desenvolver esta pesquisa na Escola Municipal Professor Severino Bezerra, situada no bairro São Benedito, no município de Pau dos Ferros-RN. Esse estabelecimento de ensino em questão foi escolhido pelo fato de dispor das turmas $8^{\circ}$ e $9^{\circ}$ ano, mantida pelo poder municipal, pois durante a pesquisa prioriza-se ter compreensão a respeito do envolvimento das escolas municipais com a questão ambiental.

A preocupação é que, as escolas em geral e as redes de ensino, atentem para a importância que tem o compromisso da disseminação da EA na efetiva formação de cidadãos comprometidos com o meio ambiente e sua preservação. Espera-se em especial que na escola campo de estudo da pesquisa, se comprove a existência do compromisso com as questões ambientais, e que ao final seja possível perceber que de alguma forma a equipe pedagógica está tentando incluir esse conteúdo na pauta das aulas ao longo do ano letivo.

Estruturalmente o trabalho contempla três partes, nas quais primeiramente discorreremos sobre os aspectos teórico-conceituais e metodológicos da Educação Ambiental, assim como, trataremos de assuntos mais particulares com relação à efetivação da EA: os problemas existentes, e quais possíveis soluções precisam ser implantadas com urgência no intuito de viabilizar uma prática mais concreta de Educação Ambiental.

Nas partes seguintes, será feita a investigação na escola em questão, a respeito da presença da EA na instituição, e um diagnóstico sobre como se trabalha a temática no dia a dia, em sala de aula, e a maneira como a mesma está sendo disposta nos documentos que regem a grade curricular da escola campo de pesquisa, com vistas a detectar como a ideia de cada autor citado nesse documento pode contribuir na elucidação de dúvidas e incertezas sobre 
como se pode trabalhar a EA e algumas indicações de como esse trabalho pode ser realizado, tanto nos âmbitos formal e não formal.

Para que fosse possível fazer um estudo mais aprofundado com relação às bases teóricas, esta pesquisa baseou-se na contribuição de alguns autores e documentos, tais como: Carvalho (2008); Guimarães (2004); Prado e Gutierrez (2008); Brasil (2007) dentre outros. Também procuramos através do estudo do Projeto Político Pedagógico (PPP) da escola, verificar se o trabalho é pautado nos Parâmetros Curriculares Nacionais (PCN), se a temática ambiental é trabalhada como tema transversal e se a interdisciplinaridade também se faz presente.

Finalmente, com o intuito de encontrar outros subsídios para a pesquisa realizamos aplicações de questionários com educadores, alunos e gestores em que foram averiguados as concepção que os mesmos têm sobre a $\mathrm{EA}$, e de que forma os docentes relacionam a temática em questão com as disciplinas que lecionam.

\section{Histórico da Educação Ambiental: o surgimento das primeiras questões sobre problemas ambientais}

Os problemas ambientais não são recentes, o que se tem hoje é o agravamento destes, gerado pela humanidade ao longo do processo civilizatório. O debate acerca destes problemas também não é recente. A Educação Ambiental se discute e se define efetivamente em documentos, eventos oficiais e conferências internacionais. Para uma melhor visualização de tais elementos no tempo e no espaço, elaborou-se a seguinte sistematização:

Tabela 1: Breve histórico da Educação Ambiental.

\begin{tabular}{|c|c|}
\hline 1962 & $\begin{array}{l}\text { Segundo Fensterseifer (2008) "nos Estados Unidos, Rachel Carson contou a "fábula do } \\
\text { amanhã" em sua obra Primavera silenciosa e lançou a semente do que se tornaria mais tarde } \\
\text { uma revolução social e cultural. [...] projetou para o espaço público o debate a respeito da } \\
\text { responsabilidade da ciência, dos limites do progresso tecnológico e da relação entre ser } \\
\text { humano e natureza". }\end{array}$ \\
\hline 1972 & $\begin{array}{l}\text { Nos demais anos citados, de acordo com os PCN foram elencados importantes encontros, } \\
\text { "Conferência das Nações Unidas para o Meio Ambiente Humano, realizada em Estocolmo: } \\
\text { estabeleceram-se o "Plano de ação Mundial" e a "Declaração sobre o Ambiente Humano" } \\
\text { (orientação aos governos) definiu-se pela primeira vez, a importância da ação educativa nas } \\
\text { questões ambientais [...]". }\end{array}$ \\
\hline 1977 & $\begin{array}{l}\text { "Conferência Intergovernamental de Educação Ambiental de Tbilisi (na CEI, Geórgia): } \\
\text { definiram-se os objetivos da Educação Ambiental e o ensino formal foi indicado como um dos } \\
\text { eixos fundamentais para consequir atingi-los". }\end{array}$ \\
\hline 1987 & $\begin{array}{l}\text { "Conferência Internacional sobre Educação e Formação Ambiental, convocada pela UNESCO } \\
\text { e realizada em Moscou, conclui-se pela necessidade de introduzir a Educação Ambiental nos } \\
\text { sistemas educativos dos países". }\end{array}$ \\
\hline 1992 & $\begin{array}{l}\text { "Conferência Rio/92: aprovou-se, entre outros documentos, a "Agenda 21", que reúne } \\
\text { propostas de ação para os países e os povos em geral, bem como estratégias para que essas } \\
\text { ações possam ser cumpridas". Em complementação a essa agenda, os países da América } \\
\text { Latina e do Caribe apresentaram a "Nossa Agenda", com as prioridades para seus países. E } \\
\text { os governos locais apresentaram a "Agenda Local". }\end{array}$ \\
\hline
\end{tabular}

Fonte: Fensterseifer (2008); Brasil (2001).

Revbea, São Paulo, V 10, N²: 318-343, 2015. 


\section{Repensando a Educação Ambiental}

São muitas as abordagens da Educação Ambiental. Algumas pessoas a entendem como ciência que reúne ecologia e sociologia, enquanto outras a veem como solução para os problemas de âmbito social. A maneira de conceber a EA se apresenta e diferencia nas formas tanto técnicas quanto subjetivas. Desse modo, elencam-se alguns destes conceitos nas perspectivas de estudiosos e pesquisadores na área.

Loureiro (2008, p. 69), define a Educação Ambiental como "uma práxis educativa e social que objetiva a construção de valores, conceitos, habilidades $e$ atitudes que viabilizem o entendimento da realidade de vida e sua atuação lúcida responsável de atores na relação sociedade-natureza". E ainda a enfatiza como elemento, num contexto mais amplo, capaz de produzir e reproduzir as relações sociais e para que haja transformação nestas, dependem de diversas modificações nos planos políticos, social, econômico e cultural.

Baeta e Castro (2008), afirmam que a Educação Ambiental constitui uma área de conhecimento que excede a interdisciplinaridade, em virtude de vários elementos interligados e imprescindíveis ao diagnóstico e prevenção que a presumem.

De acordo com Marcatto (2002), a educação ambiental é uma das ferramentas existentes para sensibilizar e capacitar a população como um todo acerca dos problemas ambientais, buscando desenvolver técnicas e metodologias que viabilizem o processo de consciência sobre a seriedade dos problemas ambientais e a urgente necessidade de atentarmos sobre eles.

Guimarães (2004) re-significa a EA como "crítica" ao compreender a necessidade de diferenciar ações educativas capazes de dar contribuição na modificação da realidade que há tempos se encontra em grave crise socioambiental.

Pode-se verificar que esses são apenas alguns conceitos existentes sobre EA, porém nada ainda fechado, pronto e acabado, tendo em vista a ampla gama de possibilidades de se conceber vários vieses para a temática em questão. O que importa no momento é averiguar o maior envolvimento possível das pessoas no que concerne a superar os problemas de cunho ambiental, de forma consciente, crítica e mobilizadora.

Portanto, a pesquisa concentra-se em relatar a abordagem que possivelmente atende as necessidades da educação contemporânea, a Educação Ambiental Crítica, que veio para dar apoio às mudanças de cunho sócio ambiental, necessárias para que haja a possibilidade futura, de se adotar posturas sustentáveis com relação à preservação do meio ambiente. 


\section{Uma abordagem sobre a Educação Ambiental crítica}

A preocupação ambiental da sociedade, em voga nos dias atuais, tem repercutido no campo educacional. A EA tem um papel relevante nas abordagens descritas por literaturas especializadas sobre educação e meio ambiente, buscando o entendimento de que a natureza não deve ser vista pelo viés do utilitarismo, mas que cada um se conscientize e se responsabilize por suas ações.

Vale ressaltar a importância da interação entre o homem e a ação educativa. Os educadores enquanto mediadores do conhecimento têm importante parcela de contribuição para a tentativa de estabelecer um ensino de cunho pragmático e inovador no que diz respeito à Educação Ambiental e as relações sociais, pois serão as ações realizadas em sociedade que surtirão efeito na questão ambiental, positivas ou negativas. Parte daí, o enfoque interdisciplinar. De acordo com Carvalho (2008, p.152), "O que essas novas educações têm em comum é o fato de tratarem as questões emergentes da vida social em uma perspectiva interdisciplinar, convocando diferentes saberes e áreas de conhecimento para compreendê-las".

O constante uso do termo Educação Ambiental, pode levar ao entendimento que talvez seja possível, apenas com um belo discurso de apoio ao verde e/ou com política de boas ações, se chegar a um vasto campo de consenso. Geralmente, ao inserir essa expressão em um projeto, forma-se a ideia de que surgirão alianças entre os educadores e que esses através da boa vontade serão capazes de ensinar os educandos a serem mais cuidadosos com o meio ambiente. A expressão passou a ser usada como um termo que reuniria tudo que se denomina de boas práticas ambientais, sem levar em consideração quais critérios definiriam essas práticas. Carvalho (2008, p.154), reforça ainda que "apenas uma visão ingênua tenta sugerir que a boa intenção de respeitar a natureza seria premissa suficiente para fundamentar nova orientação educativa apta a intervir na atual crise ecológica [...]".

No modelo da EA Crítica, a formação do sujeito se dá através da análise deste, enquanto ser social, e por meio do seu contexto histórico. A educação passa a ser vista como mediadora na formação social de conhecimentos relacionados à vida dos indivíduos. Não tem sentido formar sujeitos sem levar em consideração sua relação com o mundo em que vive e sobre o qual é responsável. Carvalho (2008, p. 156-157) acrescenta ainda que:

Nesse sentido, o projeto político-pedagógico de uma EA crítica poderia ser sintetizado na intenção de contribuir para uma mudança de valores e atitudes, formando um sujeito ecológico capaz de identificar e problematizar as questões socioambientais e agir sobre elas. 
É preciso pensar num projeto de EA de forma previamente delimitada, para quem se dirige e a que grupo social ou cultural se destina. Promover a educação considerando crenças, valores e interpretando as diferentes realidades. Dessa forma, é imprescindível atuar no dia a dia escolar e não escolar, dando lugar a novos questionamentos, situações de aprendizagem, resolução de problemas e buscar articular a escola com os ambientes locais e regionais onde está inserida. Carvalho (2008, p.151), afirma que:

Ao constituir-se como prática educativa, a EA posiciona-se na confluência do campo ambiental e as tradições educativas, as quais vão influir na formação de diferentes orientações pedagógicas no âmbito da EA ou, dito de outro modo, produzir diferentes educações ambientais.

As escolas ganham destaque na tentativa de inserir a EA em seus currículos. Têm vantagens por serem literalmente palcos propícios para viabilizar mudanças de comportamento e modos de pensar da classe escolar, através de métodos de ensino inovadores e, melhor ainda, prazerosos, que propiciem uma reflexão mais crítica a cerca dos problemas ambientais que enfrentam e a conscientização dos hábitos.

Os trabalhos referentes à Educação Ambiental na escola devem priorizar inicialmente a sensibilização dos agentes que a compõem: o corpo docente, discente e funcionários em geral, para logo em seguida ter como objetivos ampliar o grau de conhecimento da comunidade, tratar de viabilizar condições para que o trabalho com a EA na instituição seja permanente.

Desse modo, Guimarães (2004, p. 32), conclui: "Portanto, na educação formal, certamente esse processo educativo não se basta dentro dos muros de uma escola, o que explicita a interface entre esta Educação Ambiental e a Educação Popular." É sabido que, a inclusão da Educação Ambiental Crítica nas escolas não é tarefa fácil, pois existem grandes dificuldades com relação às atividades de sensibilização e formação, na implantação de atividades e projetos e, mais ainda, na manutenção e continuidade dos já existentes.

Fatores como o tamanho da escola, números de alunos e de professores, a vontade da diretoria de realmente inserir um projeto ambiental que vá alterar a rotina na escola, não estão descartados. Projetos realizados por pequenos grupos ou atividades isoladas não são capazes de produzir a mudança de mentalidade necessária, para que a atitude de reduzir o consumo, reutilizar e reciclar, dentre outras atividades ambientais, se estabeleça e transcenda para além do ambiente escolar. Com relação ao exposto, Guimarães (2004, p. 32), ressalta: 
A proposta da ação pedagógica da Educação Ambiental Crítica vir a ser desenvolvida através de projetos que se voltem para além das salas de aula pode ser metodologicamente viável, desde que os educadores que a realizem, conquistem em seu cotidiano a práxis de um ambiente educativo de caráter crítico.

Portanto, deve-se ir ao encontro de alternativas que deem impulso à contínua reflexão, que culminem em uma mudança de mentalidade, pois apenas dessa forma pode-se estabelecer nas escolas a verdadeira Educação Ambiental Crítica, com atividades e projetos que serão frutos do desejo de toda a comunidade escolar em construir um futuro no qual seja possível viver em um ambiente equilibrado, com os outros seres vivos e com os semelhantes.

\section{A importância de políticas públicas na formação de educadores ambientais}

De certa forma, a Educação Ambiental se fundiu no ensino fundamental do país, sendo a ação dos $\mathrm{PCN}^{3}$ de grande importância para esse processo. A disposição dos temas transversais em especial "meio ambiente" vem contribuindo para a disseminação da EA nas escolas, especialmente no nível fundamental. Porém, para que se alcance uma dimensão maior, faz-se necessária a efetivação de algumas políticas públicas, em escala federal, estadual e municipal, para que o processo de formação desses educadores ambientais não cesse e precisam ter apoio pedagógico e de gestão para o enriquecimento da prática.

Quando se ressaltam educadores ambientais, não se diz ou se propaga uma nova categoria de educadores, falam-se dos educadores que trabalham a educação convencional, que tem por obrigação e consciência incluir a temática ambiental em seus planos de aula. Em face do período de mudança que atravessa a educação no Brasil e no mundo, em que o ensino fragmentado está perdendo espaço para uma educação crítica e reflexiva, é esse tipo de educação que fará a diferença, promoverá mudança nos valores e comportamentos dos cidadãos que por ventura terão acesso a esse novo modelo educacional. De acordo com os PCN :

\footnotetext{
3 Parâmetros Curriculares Nacionais. "Os Documentos apresentados são resultado de um longo trabalho que contou com a participação de muitos educadores brasileiros e tem a marca de suas experiências e de seus estudos, permitindo assim que fossem produzidos no contexto das discussões pedagógicas atuais" BRASIL. Secretaria de Educação Fundamental. Parâmetros Curriculares Nacionais: terceiro e quarto ciclos do ensino fundamental: introdução aos parâmetros curriculares nacionais/ secretaria de Educação Fundamental. Brasília: MEC/SEF, 2001. P.05 174 p.
} 
Neste final de século, de acordo com o depoimento de vários especialistas que vêm participando de encontros nacionais e internacionais, o Brasil é considerado um dos países com maior variedade de experiências em Educação Ambiental, com iniciativas originais que, muitas vezes, se associam a intervenção na realidade local. Portanto, qualquer política nacional, regional ou local que se estabeleça deve levar em consideração essa riqueza de experiências, investir nela, e não inibi-la ou descaracterizar sua diversidade. (BRASIL, 2001. p.181).

Somente a partir de 1999 que a educação ambiental no Brasil passou a ser regida através de legislação específica tendo como marco inaugural a Lei 795/99, que estabeleceu a Política Nacional de Educação Ambiental (PNEA). A Lei afirma, em seu Artigo $2^{\circ}$, que "a Educação Ambiental é um componente essencial e permanente na Educação nacional, devendo estar presente, de forma articulada, em todos os níveis e modalidades do processo educativo, em caráter formal e não formal". O Artigo $3^{\circ}$, inciso II, completa a ideia ao estabelecer que cabe às instituições educativas promover a Educação Ambiental de maneira integrada aos programas educacionais que desenvolvem".

Ao analisar os artigos anteriormente citados, percebemos que é dada aos educadores uma tarefa bastante clara, a de promover a EA de maneira integrada. Como fazê-la se não tiverem as devidas condições necessárias para que o ensino aconteça efetivamente? Entende-se que há necessidade de investimentos por parte dos poderes locais na (pró) formação dos "educadores ambientais", não apenas propiciar cursos que os tornem mais um dentre os muitos multiplicadores espalhados pelo mundo como reforça Guimarães (2004, p. 134):

Mas que formação? Uma que supere as propostas que proliferam de formar multiplicadores para educação ambiental. Como se bastasse alguns professores multiplicarem as informações e técnicas metodológicas apreendidas em um curso, para os demais professores da escola. E quando cessam esses cursos por descontinuidade das políticas educacionais, ou quando o professor multiplicador sai da escola?[...]

De fato, não se podem descartar os avanços na área da EA que tem mudado o discurso, antes meramente informativo. Nos dias atuais, buscam-se inovações, ações críticas e reflexivas, que possam atenuar a problemática ambiental que se enfrenta. Por isso, é que se reverencia a escola como local mais propício para a exploração da temática. Sendo proposta de forma 
adequada, com mobilização de seus integrantes: gestores, educadores, alunos e comunidade em geral, visando à ampliação do entendimento público. Para que juntos desenvolvam iniciativas que modelem novos comportamentos sociais, éticos, culturais e ambientais sustentáveis.

O educador ambiental não deve se conter em apenas ser o locutor de meras informações, como acontecem em metodologias de ensino como palestras, capacitações e exposições, mas sim, ansiar por mudanças. Reforça Guimarães (2004, p. 139):

Intervenção para transformação da sociedade que, em sua intencionalidade, provoque movimentos de problematização, questionamentos e práticas de transformações de valores, hábitos e atitudes, individuais e coletivos, de forma que sejam inseridos no cotidiano daqueles (indivíduos em comunidade) que estão sofrendo a intervenção do processo educativo.

Parece conveniente confirmar pelo exposto, que as intervenções de EA nas escolas e comunidade em geral, são de suma importância para o sucesso das ações planejadas ao longo do processo de sensibilização da sociedade, para uma nova forma de viver.

É importante frisar a necessidade do engajamento das instituições governamentais, no que diz respeito aos movimentos de causas comuns como saúde, direitos humanos, educação e meio ambiente. Todos com igual nível de importância, e deixados muitas vezes a esmo pelas políticas públicas. A sociedade civil precisa se organizar em prol dessas causas, tornando-se contra partida nas reivindicações de seus direitos. Em especial que lutem pela preservação do meio ambiente para garantir o bem estar das futuras gerações. Segundo Prado e Gutierrez (2008, p. 14):

O sentido de trabalhar por um meio ambiente sadio constrói-se num fazer diário, numa relação pessoal e grupal e, por isso, a tomada de consciência ambiental cidadã só pode traduzir-se em ação efetiva quando segue acompanhada de uma população organizada e preparada para conhecer, entender e exigir seus direitos e exercer suas responsabilidades.

Segundo Prado e Gutierrez (2008), "esse cidadão, quando se organiza e participa na decisão de sua própria vida, adquire poder político e uma capacidade de mudança coletiva", ou seja, descrevem o cidadão crítico e consciente, como um sujeito ativo, no que diz respeito à responsabilidade ambiental que cada um deve exercer. Nesse sentido, essas pessoas compreendem, reclamam e exigem seus direitos ambientais, aos setores 
sociais responsáveis e como acima foi citado, não fogem de suas responsabilidades.

Ainda segundo estes autores, essa mudança coletiva citada trata da necessidade urgente da união de grupos de importância social e política, dentre eles: parlamentares, autoridades locais, associações de consumidores, grupos religiosos, educadores e meios de comunicação, para que juntos, possam contribuir com responsabilidades variadas, usando de muita criticidade para a melhoria da vida cidadã da região, na perspectiva de preservação do meio ambiente.

Pelo exposto, percebe-se a importância da existência de políticas públicas mais eficazes e permanentes, como também a necessidade de subsídios pedagógicos com bases firmes para nortear a educação e educadores na sua prática como todo. Portanto, optou-se por ressaltar a relevância que tem um dos documentos de destaque no ensino fundamental os PCN, em se tratando de diretrizes curriculares para as escolas, não como algo pronto e acabado, mas, como subsídio para o trabalho das diferentes áreas de ensino, bem como a importância da discussão de questões relativas à sociedade brasileira contida nos temas transversais.

\section{Parâmetros Curriculares Nacionais (PCN) e a disposição dos temas transversais}

Os Parâmetros Curriculares Nacionais (PCN) são pautados em normas legais, objetivando dar contribuição na busca de respostas aos problemas que por ventura venham ser identificados no ensino fundamental, bem como, dar suporte às discussões voltadas para o desenvolvimento dos projetos educativos das escolas e subsídio teórico/ metodológico para os planos de aulas. Visando uma modificação do ensino desse nível, no intuito de atender as demandas da sociedade brasileira. Segundo o documento oficial PCN introdução:

Os Parâmetros Curriculares Nacionais nascem da necessidade de se construir uma referência curricular nacional para o ensino fundamental que possa ser discutida e traduzida em propostas regionais nos diferentes estados e municípios brasileiros, em projetos educativos nas escolas e nas salas de aula (BRASIL, 2001, p. 09).

Nos PCN de terceiros e quarto ciclos ${ }^{4}$ do Ensino Fundamental, partes introdutórias, são abordadas as respectivas áreas de ensino: Língua

\footnotetext{
${ }^{4}$ Cada ciclo corresponde a dois anos de escolaridade no ensino fundamental. Nesse caso trata-se dos anos (séries) finais do ensino fundamental.
}

Revbea, São Paulo, V 10, N²: 318-343, 2015. 
Portuguesa, Matemática, História, Geografia, Ciências Naturais, Educação Física, Arte e Língua Estrangeira. "Em todas buscou-se evidenciar a dimensão social que a aprendizagem cumpre no percurso de construção da cidadania, elegendo, dessa forma conteúdos que tenham relevância social e que sejam potencialmente significativos para o desenvolvimento de capacidades" (BRASIL, 2001, p.58). Em comum, para cada área mencionada, há uma parte no documento específica, que faz a análise do ensino de cada área distintamente, elencando sua importância para a formação do aluno do ensino fundamental. Dispondo da proposta ${ }^{5}$ curricular minunciosamente sobre objetivos, conteúdos, avaliação e orientações didáticas para cada ciclo.

No entanto, para ir ao encontro das exigências da sociedade atual, fazse necessário que a escola trabalhe com questões que possam estar ligadas diretamente à vida dos alunos. Algumas referências indicam o debate transversal de temas sociais na escola, tendo em vista considerá-los na sua forma mais complexa, sem resumi-los a apenas uma área. No que diz respeito à transversalidade o PCN introdutório afirma que:

A transversalidade pressupõe um tratamento integrado de áreas e um compromisso com relações interpessoais no âmbito da escola, pois os valores que se quer transmitir, os experimentados na vivência escolar e a coerência entre eles devem ser claros para desenvolver a capacidade dos alunos de intervir na realidade e transformá-la, tendo essa capacidade relação direta com o acesso ao conhecimento acumulado pela humanidade (BRASIL, 2001, p. 65).

Em face disso, elencam-se os temas transversais que compõem os PCN: Ética, Saúde, Meio Ambiente, Pluralidade Cultural, Orientação Sexual, Trabalho e Consumo. Os temas citados não implicam na constituição de novas áreas de ensino, mas um grupo de temas que se apresentam transversalizados, ou seja, interpõem-se a compreensões de diversas áreas, bem como aos objetivos, conteúdos e consequentemente orientações didáticas. Segundo Medina (2001, p. 24), "considerar a Educação Ambiental como o eixo dos conjuntos dos temas transversais facilita sua inserção no currículo escolar e atinge os objetivos propostos nos PCN'. Por isso, Sato afirma algo bastante relevante sobre o porquê de não existir uma disciplina voltada unicamente para questões ambientais:

\footnotetext{
${ }^{5}$ Diz respeito à constituição de uma referência curricular disposta na $2^{\text {a }}$ parte do documento de introdução dos PCN, que vai da pág.71-81. BRASIL. Secretaria de Educação Ambiental. Parâmetros Curriculares Nacionais: terceiro e quarto ciclos do ensino fundamental: introdução aos parâmetros curriculares nacionais/ secretaria de Educação Fundamental. Brasília: MEC/SEF, 2001. 174 p.
} 
O pensamento cartesiano, que conduziu a ciência pelos aspectos específicos, e a diversidade de acontecimentos ambientais não permitem a criação de uma disciplina de Educação Ambiental, pois dificilmente se encontra um profissional de formação polivalente que detenha todos os conhecimentos inerentes à multidimensionalidade associada à questão ambiental (SATO, 2004. pág. 24).

Os temas transversais têm ligações estreitas com a questão ambiental, porém em virtude da temática da pesquisa em questão deteve-se ao tema transversal Meio Ambiente, iniciaremos ressaltando um trecho ainda do documento introdutório aos PCN, no qual se afirma que:

A principal função do trabalho com o tema Meio Ambiente é contribuir para a formação de cidadãos conscientes, aptos a decidir e a atuar na realidade socioambiental de modo comprometido com á vida, com o bem estar de cada um e da sociedade, local e global (BRASIL, 2001, P.67.)

Ao elencar, o termo socioambiental, abre-se um leque de possibilidades para que as escolas em geral possam construir um trabalho com caráter revolucionário, construindo novos valores pautados na sustentabilidade. Para isso, faz-se necessário que haja realmente o interesse por parte dos educadores e gestores das escolas na implantação desse referencial teórico. Espera-se que os temas transversais possam juntos com as demais áreas, contribuir para um ensino de cunho transformador. Corroborando com isso o PCN (Temas Transversais) afirmam:

A transversalidade diz respeito à possibilidade de se estabelecer, na prática educativa, uma relação entre aprender conhecimentos teoricamente sistematizados (aprender sobre a realidade) e as questões da vida real e de sua transformação (aprender na realidade e da realidade). E a uma forma de sistematizar esse trabalho e incluí-lo explícita e estruturalmente na organização curricular, garantindo sua continuidade e aprofundamento ao longo da escolaridade (BRASIL, 2001, p.30).

O trabalho relacionado ao meio ambiente como tema transversal nos PCN vai ao encontro de mudanças comportamentais, no intuito de inibir e extinguir as atitudes insustentáveis, como jogar lixo em ambientes sociais, seja na escola, nas ruas de bairros em seus locais de trabalho, sem a menor preocupação de como estão afetando o meio ambiente, dentre outras atitudes referentes a essas. Toda a sensibilização e mobilização sobre as questões 
ambientais não poderiam nem deveriam ser atribuídas unicamente à escola, porém ela tem o poder de transformar atitudes.

Por isso, é mais viável que este trabalho seja iniciado nas instituições escolares, considerando os aspectos físicos, biológicos e especialmente a interação do ser humano com a natureza. Apesar de se atribuir às escolas grande responsabilidade na formação de cidadãos conscientes no que concerne a problemas ambientais, não podemos esquecer de que se na grade curricular das instituições a EA se apresenta de forma transversal, nos lares deveria ser assim também. Em todos os momentos deveria acontecer a mediação no tocante às ações dos mais próximos para preservação do meio ambiente, em todos os sentidos: sociais, políticos e culturais.

Felizmente a sociedade tem se mostrado mais preocupada com relação à degradação do meio ambiente, pode-se averiguar essa informação nos noticiários de TV, jornais, redes sociais e nos discursos dos poderes locais, regionais e mundiais. A solução de tais problemas está entre as prioridades dos interesses dos governantes. Portanto, fica evidente a importância e a necessidade de educar crianças, jovens e adultos numa perspectiva transversal e interdisciplinar, para que entendam que a natureza é fator primordial para nossa subsistência.

\section{Caminho que leva a interdisciplinaridade}

De certo, o tema interdisciplinaridade é um dos ápices nas instituições escolares da contemporaneidade. É uma busca incessante para vislumbrar de forma mais ampla a realidade, uma forma de descentralizar o ensino, em que cada área de ensino preocupa-se apenas em reproduzir o conteúdo que lhe cabe, deixando de lado a transversalidade e consequentemente a interdisciplinaridade que as deve compor.

Certamente, a interdisciplinaridade encontra alguns obstáculos para sua efetivação, não apenas nos ensinos fundamental e médio, já que o ensino das instituições superiores ainda não se apresenta de forma integrada, e o elo entre as áreas de ensino dificilmente existe. Segundo Pena-Veja (2008, p. 21), dentre as várias descrições:

A interdisciplinaridade é definida como "um procedimento de união dialógica das contribuições disciplinares necessárias para a análise de um objeto complexo". O qualificativo "dialógico" é empregado para significar uma diferença fundamental com a pluridisciplinaridade, na qual as contribuições das disciplinas são simplesmente justapostas.

Ao contrário, às vezes, algumas temáticas dentre elas a questão ambiental passa despercebida, salvo engano quando se trata de um curso 
específico da área em questão. Encontram-se tão preocupados na formação técnica que se esquecem do social. Corroborando com isso, Dias (2001, p. 73), afirma:

Essa situação é especialmente nutrida pelas universidades brasileiras. Apáticas, vaidosas, obsoletas e dessintonizadas com a realidade, continuam imersas em sua prática acadêmica utópica [...]. Continuam produzindo profissionais que refletem o seu despreparo e vão engrossar o rol dos devastadores.

Não se podem descartar as inúmeras tentativas de que a interdisciplinaridade venha fazer parte integralmente das aulas do dia a dia, de modo que cada educador com seu conhecimento específico venha juntar-se aos demais colegas para que o ensino se torne mais rico e amplo. Embora, a interdisciplinaridade exista mais efetivamente no discurso do que na prática, não se pode descrer da possibilidade de que no futuro seja efetivamente atribuído aos currículos escolares e planos de aula esse caráter interdisciplinar. Tudo isso não se dará de um dia para o outro, segundo Carvalho (2008, p.129):

Nos caminhos da interdisciplinaridade, uma "receita pronta" seria algo muito antagônico aos ideais pretendidos. Essa busca exige disponibilidade para construir as mediações necessárias entre o modelo pedagógico disciplinar, já instituído, e as ambições de mudança. A construção de práticas inovadoras não se dá pela reprodução, mas pela criação, pela readaptação e, sobretudo, no caso da interdisciplinaridade, por novas relações de organização do trabalho pedagógico.

Vivenciar nas instituições escolares, esse avanço significativo para as diversas abordagens educacionais e por que não ambientais, será certamente uma grande conquista para a educação em si, no intuito de propiciar às futuras gerações uma educação com vistas à integridade de valores e mudanças comportamentais. Portanto, os educadores que procuram integrar ao ensino as questões ambientais, de forma transversal e interdisciplinar, têm que primar pela cooperação dos demais colegas das diversas áreas.

\section{Metodologia}

A metodologia se refere a um estudo de caso, com observação participante, relacionada ao diagnóstico da Educação Ambiental na Escola Municipal Professor Severino Bezerra, situada no município de Pau dos FerrosRN. Nossa pesquisa teve como uma de suas prioridades a observação da grade curricular e do cotidiano escolar, para detectar se realmente a EA permeia todas as áreas de ensino. Para que se chegasse à tais confirmações, foram necessárias visitas frequentes a instituição de ensino, para 
primeiramente conhecer o espaço físico, a equipe administrativa, pedagógica e docente que a compõe. Depois, através de observação participante foi possível acompanhar as turmas citadas em tarefas extraclasses. Os estudantes trataram nessas aulas de campo, de informarem a população, sobre questões ambientais de cunho biológico e social, no intuito de informá-la e sensibilizá-la. Os alunos que participaram desse projeto foram escolhidos por se tratarem de jovens em faixa etária de maior maturidade para compreensão do objeto de estudo: a questão ambiental.

Em outra etapa da pesquisa foram aplicados questionários semiestruturados aos gestores, docentes do ensino fundamental II e os discentes pré-selecionados. Ao todo foram entrevistados 09 (nove) professores, 03 (três) gestores e 68 (sessenta e oito) alunos. Os questionários continham questões ambientais relevantes à pesquisa em questão. As perguntas foram selecionadas de acordo com o provável nível de aprofundamento no assunto específico para cada grupo. Sendo 10 (dez) questões para cada questionário. Para os alunos foram feitas 06 (seis) questões subjetivas e 04 (quatro) objetivas, para professores e gestores o questionário foi composto apenas por perguntas subjetivas.

O Projeto Político Pedagógico (PPP) da escola também foi analisado, com o intuito de, após as análises dos dados, verificar as condições de cooperação na atuação dos educadores com relação ao ensino interdisciplinar e sua concepção sobre Educação Ambiental, se realmente a EA perpassa por todas as áreas de ensino, e se caso contrário quais são os argumentos e/ou implicações para o fato.

Além disso, foi feita a análise das entrevistas, para que fosse possível diagnosticar se a interdisciplinaridade realmente acontece, se os professores e a direção da escola se interessam pelas questões ambientais, nas perspectivas naturais e sociais e quais concepções têm sobre Educação Ambiental.

\section{Resultados e discussões: narração das ações desenvolvidas}

Após a aplicação dos questionários e acompanhamento das aulas extraclasse, foi possível ter base de como funciona a inclusão da Educação Ambiental na escola em questão. Nessa perspectiva, destacam-se algumas observações sobre as aulas de campo com os alunos do $8^{\circ}$ e $9^{\circ}$ anos da Escola Municipal Professor Severino Bezerra.

No período de realização da pesquisa, podemos observar algumas ações na escola, nas quais os alunos estiveram envolvidos. $O$ trabalho sobre Educação Ambiental, já havia sido realizado em anos anteriores, desde então vem sofrendo adaptações. A disciplina que estava à frente do trabalho era a de Ciências Naturais, e a professora teve ajuda indireta das outras disciplinas, através de sugestões, assim como, da coordenação/ gestão que deu o suporte necessário para a realização do trabalho. 
Foi possível acompanhar todo o desenvolvimento dos trabalhos, podemos inclusive participar diretamente de uma das ações. Dentre elas destacam-se as relacionadas à reciclagem e aos crimes ambientais. Os alunos puderam levar às escolas e estabelecimentos comerciais escolhidos para a realização das ações, informações relevantes sobre a temática em questão. Algumas imagens que determinam o objetivo da ação foram selecionadas. As Figuras 1, 2 e 3 são da ação extraclasse denominada como Point Ecológico, em que as turmas de $8^{\circ}$ e $9^{\circ}$ anos saiam nos supermercados pedindo doação de sacolas plásticas para depois realizarem um trabalho de ação multiplicadora, mostrando os malefícios que as sacolas plásticas trazem para o meio ambiente, o tempo que cada uma levaria para se desintegrar, e quais diferenças existentes entre os tipos de materiais utilizados na fabricação dessas sacolas.

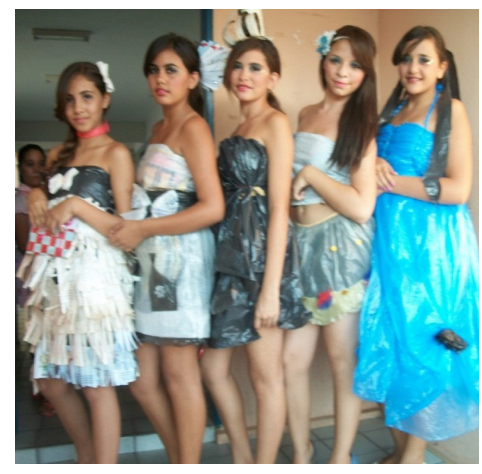

Figura 1: Modelos de roupas recicláveis. Fonte: acervo da autora.

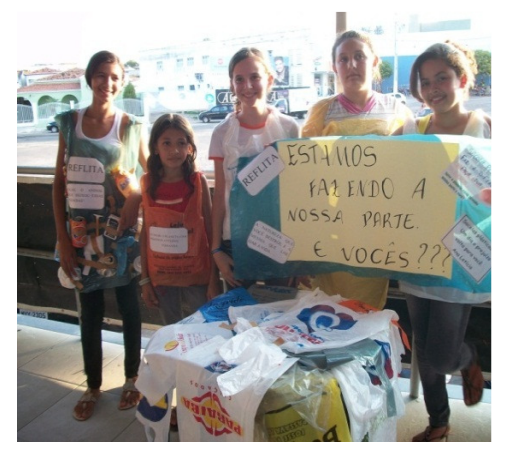

Figura 2: Amostra das várias composições das sacolas plásticas. Fonte: acervo da autora.

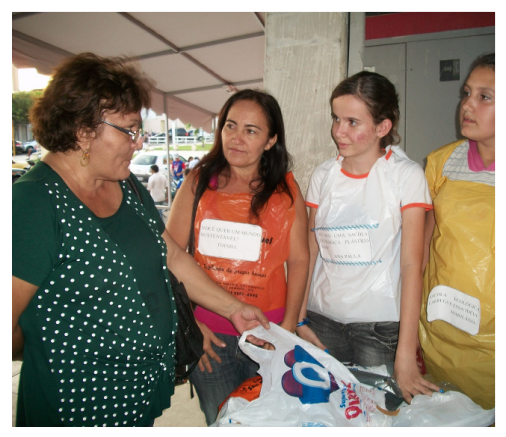

Figura 3: Explicação sobre as diversas composições das sacolas plásticas. Fonte: acervo da autora.

Foi um trabalho bastante interessante, que poderia ser abraçado por empresários e alguns comerciantes, porque por meio do conhecimento das informações dada pelos estudantes, poderiam se conscientizar e fazer a troca das sacolas convencionais pelas sacolas ecológicas reutilizáveis, pois elas diminuiriam a circulação dos descartáveis e amenizariam um pouco o processo de degradação do meio ambiente.

Nas figuras 4 e 5, mostram-se grupos de alunos das turmas supracitadas fazendo visita a Escola municipal São Benedito de nível fundamental I, em que através de uma peça teatral os mesmos mostraram alguns dos crimes ambientais cometidos com mais frequência na região. Por se tratar de um público alvo composto na maioria por crianças do nível fundamental I, utilizou-se de linguagem bastante acessível e divertida. Assim como, através do uso da criatividade e da junção do lúdico com a parte informativa transmitiram a mensagem central que era preservação do meio 
ambiente, e de como é importante a interação entre os agentes envolvidos: os seres humanos e o meio em que vivem.

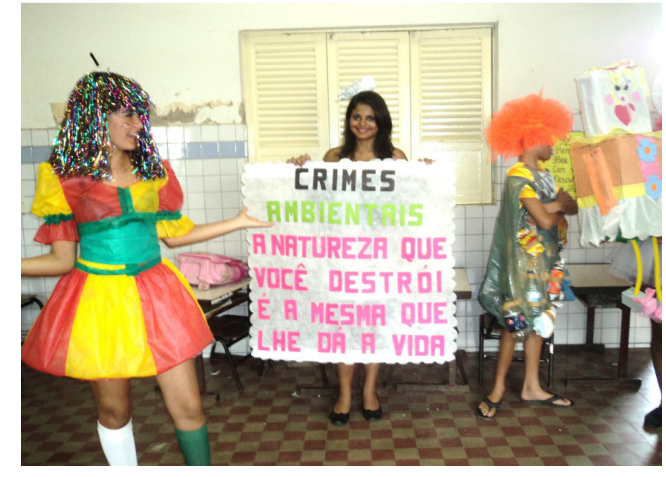

Figura 4: Explanação sobre os crimes ambientais. Fonte: acervo da autora.

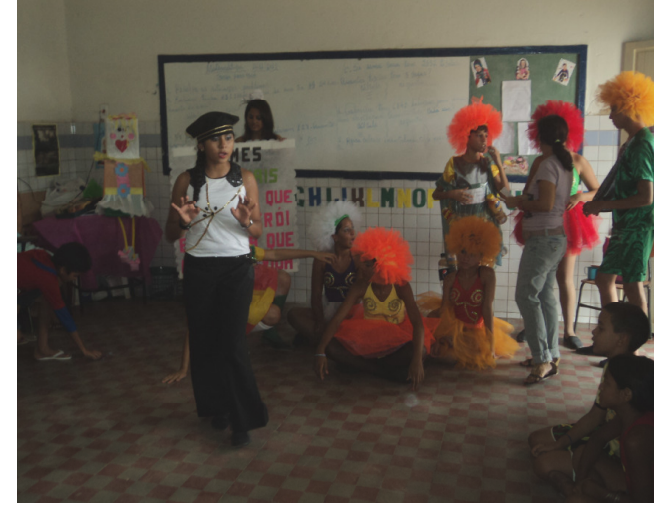

Figura 5: Questionamentos sobre os possíveis crimes ambientais existentes na cidade. Fonte: acervo da autora.

Apesar das ações demonstradas acima, quando fizemos a análise do documento que rege a escola, o Projeto Político Pedagógico (PPP), constatamos uma contradição. Em momento algum na leitura do documento se fez menção à $E A$, apesar de que os gestores aos serem perguntados durante 0 questionário sobre a existência das questões ambientais no PPP da escola enfatizaram sua presença no documento.

O documento é composto por partes distintas. Inicia-se com uma justificativa onde é descrita a necessidade de sua construção e a caracterização da escola, depois parte para a explanação do referencial teórico pautado nas mudanças ocorridas na década de 1990. Tratam como maior marco educacional a LDBEN (Lei de Diretrizes e Bases da Educação Nacional).

Dá ênfase ao ensino interacionista, cita por vezes Vygotsky, porém, os PCN só são referenciados para ressaltar que é uma tarefa difícil tê-los por base. No que diz respeito ao ensino de Artes e Educação Física na escola, afirmam "trabalharem com profissionais sem a devida capacitação nessas duas áreas, e com escassez de recursos materiais". Infelizmente não existe um trecho que seja destinado ao trabalho de cunho ambiental, nada que priorize a transversalidade e tão pouco a interdisciplinaridade entre as áreas de ensino.

\section{Interpretações dos resultados obtidos com a aplicação dos questionários}

$\mathrm{Na}$ aplicação dos questionários aos alunos, estes compostos de 10 (dez) questões mescladas entre 03 (três) objetivas e 06 (seis) subjetivas, nos remete a importância de os alunos terem em mente a necessidade de 
compreenderem a EA. As análises feitas são de cunho quantitativo e qualitativo. A primeira questão consiste no questionamento da ideia que eles têm sobre meio ambiente. Sobre a questão, $44 \%$ dos alunos responderam que o meio ambiente era tudo o que os cercava, o lugar em que vivem; $3 \%$ não responderam; 39\% dizem ser a natureza e 14\% dos alunos afirmam ser tudo que está sendo preservado e limpo.

A grande maioria dos alunos concebe o meio ambiente como sendo o lugar onde vivem, estudam, se relacionam, enfim, tudo o que os cercam. Vale observar que alguns alunos entendem o meio ambiente como algo absolutamente natural, relacionado basicamente à biologia, e o mais intrigante é o fato de enfatizarem o meio ambiente como algo que deve ser primordialmente preservado e limpo, nos fazendo concluir que por esta ótica seria bem mais fácil evitar o agravamento da atual situação de degradação do meio ambiente.

Ao serem questionados na segunda questão acerca das formas de degradação do meio ambiente que tivessem conhecimento, os alunos que responderam a pergunta primando por respostas curtas bem próximas das suas realidades. A saber: 3\% não responderam. 38\% afirmaram ser 0 desmatamento; $7 \%$ as queimadas; $41 \%$ todos os tipos de poluição; $6 \%$ especificaram os lixões a céu aberto; $5 \%$ aquecimento global. As respostas foram ao encontro das discussões em sala de aula.

Algumas das respostas podem ter sido fruto da ação extraclasse que os alunos fizeram sobre crimes ambientais, em que eles enfatizaram em sua fala os crimes cometidos no dia a dia, que de tão corriqueiros, não são atualmente tratados com as devidas precauções, como por exemplo, o desmatamento e as queimadas, que pelo fato de na nossa realidade não ocorrerem casos que afetam grandes proporções, passam despercebidas.

Em seguida, foram questionados sobre o tema chave da pesquisa em questão: Para você o que é Educação Ambiental? O maior percentual 58\% dos alunos responderam que era a preservação ambiental; $23 \%$ um tipo de ensino que mostra como cuidar da natureza; 14\% consciência ecológica (mudança de atitudes) e ainda 5\% que não tiveram nada a declarar. Estima-se que as respostas tenham sido formuladas de acordo com os conhecimentos prévios, aliados às discussões em sala de aula sobre o assunto ao longo do ano letivo.

Embasados também das informações que foram disseminadas sobre a Educação Ambiental, todas com foco na importância de sua efetivação para a melhoria de vida das pessoas, associado a preservação do ambiente. Estas informações foram surgindo de diferentes canais de veículos de informação, desde as grandes emissoras de televisão, as redes sociais, como também através de programas locais. Estamos todos interligados, devemos nos preocupar em não perder de forma alguma essa relação de ligação também com a natureza. 
$\mathrm{Na}$ quarta questão, os estudantes foram perguntados por quais diciplinas eram trabalhadas as questões ambientais. As disciplinas que se destacaram nas respostas dos alunos, foram Geografia e Ciências naturais ambas obtiveram maior percentual de respostas $77 \%$ e os $23 \%$ restantes foram divididos para as demais disciplinas. Através das respostas podemos averiguar a contribuição dada pelas disciplinas com relação a essa temática, e percebemos que a transversalidade do tema em questão não acontece na integra.

A quinta questão perguntava sobre as questões ambientais que já haviam sido discutidas em sala de aula. Ganharam destaque a água, solo, lixo, legislação, animais, vegetação, problemas socias, efeito estufa. Os temas em questão são trabalhados em sua maioria nas disciplinas de Ciências, Geografia e História.

Já a sexta questão questionava quais metodologias são usadas pelos professores para a exposição da temática ambiental, e os alunos elencaram alguns procedimentos tais como: aulas expositivas com auxilío apenas do livro didático, utilização de videos e internet, bem como trabalhos práticos e de campo.

Vale salientar aqui, que os professores estão em busca de atrativos para estimular a aprendizagem dos alunos e aumentar seu interesse para com a temática em questão. Embora essa fase entusiasta fique muitas vezes no meio do caminho, ou melhor, em algumas épocas do ano. O certo seria transversalizar a EA com todas as áreas de ensino, isso não quer dizer que em todas as aulas ministradas devem elencar a questão, mesmo por que seria impossível. Porém, sempre que surgirem situações em que os preceitos da EA sejam cabivéis de fazer parte da discussão, ligada à disciplina que porventura estiver sendo aplicada, os educadores podem e devem fazer essa ponte.

Não se pode deixar de falar sobre os problemas ambientais que os alunos observam na rua e no bairro em que moram, e eles foram elencados na sétima questão. A maioria das respostas dadas pelos dicentes, destacaram a falta de saneamento básico e a grande quantidade de lixo espalhados pelas ruas. De certa forma esses são os problemas mais comuns nos dias de hoje, sejam nas pequenas ou nas grandes metropóles.

Diante dessa realidade os alunos foram indagados na oitava questão sobre como eles lidam com essa situação de desrespeito ao meio ambiente. Foram $99 \%$ os que responderam que se importavam com os problemas, por que "estes causam doenças na população", diziam ser "falta de respeito não se importar já que é o planeta em que vivemos e se não nos importarmos daqui há alguns anos só irá existir lixo" e que aos poucos "o mundo irá acabar".

Fica claro a ânsia que eles têm por mudança, sabe-se que isso não acontece a curto prazo, o que podemos fazer enquanto educadores é incentivar as boas ações e práticas sustentáveis para que esse processo de 
degradação seja mais lento e cause menos prejuízo ao meio ambiente. Efetivando uma educação transformadora e crítica, voltada para a sensibilização e consequente conscientização.

Sendo assim, não é recomendável deter-se apenas a classe estudantil, e sim prepará-los para que possam ir além dos muros da escola, levando informação a comunidade em geral. Cada um fazendo a parte que lhe cabe, estarão contribuindo para o bem estar presente e o futuro das novas gerações. A EA deve se fazer presente na educação formal, tanto quanto na educação não formal, para que juntos possam intervir na modificação da realidade local com vistas a novos padrões de vida baseados na sustentabilidade.

$\mathrm{Na}$ nona questão os estutantes foram interrogados sobre quem ou o que seria responsável pelo surgimento de problemas ambientais. Cerca de $100 \%$ dos alunos, concordam ser o homem responsável pela situação de degradação que se encontra o planeta.

Por fim, no décimo questionamento os estudantes foram perguntados sobre o que achavam que podia ser feito para melhorar o meio ambiente de sua escola e de sua cidade. Cerca de $29 \%$ dos discentes acreditam que seria diminuição da poluição, tendo mais lixeiras espalhadas pelo ambiente; $29 \%$ coleta seletiva e $48 \%$ acreditam que deveria ser a conscientização da população através de (campanhas, palestras) para que preservem o meio ambiente. De acordo com as respostas dadas os discentes estão no caminho certo, e assim fica minimamente demonstrado o nível de compreensão que os alunos de $8^{\circ}$ e $9^{\circ}$ anos têm acerca das questões ambientais.

Já aos professores foram aplicadas questões tipo discursivas voltadas à temática. A primeira questão interrogava-os sobre qual disciplina lecionavam na escola. O segundo questionamento perguntava o que os mesmos entendiam sobre meio ambiente. De acordo com as respostas de alguns professores, o meio ambiente diz respeito ao lugar em que se vive; 0 ecossistema; conjunto de unidades ecológicas e por último um conjunto de composição biótica e abiótica. As respostas sinalizam de forma sintetizada, porém, significativa de quão é vasto o campo de estudo sobre o meio ambiente, pois, cada um a sua maneira conseguiu resumir sua compreensão acerca desse conceito tão amplo.

$\mathrm{Na}$ terceira questão, destacamos o relato de um dos professores acerca da sua compreensão sobre Educação Ambiental: "É uma prática que visa formar cidadãos conscientes e preocupados com as gerações futuras, [...], compreendendo o mundo como uma rede em que tudo se integra e uma ação impensada pode gerar problemas futuros". Está implícito na resposta a ideia que a EA tem como o objetivo viabilizar ações sustentáveis, visando a integridade do meio ambiente e o bem estar da população. Os demais professores mantém a mesma linha de raciocínio da resposta supracitada. 
Nesse contexto, há de se considerar o papel que a escola tem nesse processo de construção do conhecimento. Foi importante saber na quarta questão se a instituição incentiva à inclusão da temática ambiental nos planos de aula das disciplinas. A resposta obtida foi unânime entre os professores, estes afirmaram que a escola dá todo apoio para que haja essa integração da $E A$ às demais áreas de ensino.

Indentificou-se na quinta pergunta, que enfocava a forma como se trabalha a questão ambiental nas aulas, a presença do trabalho com projetos que envolvem todas as disciplinas foi bastante frisado, bem como as atividades extraclasse, em que $50 \%$ das disciplinas, planejam por vezes aulas com realização de atividades tais como: visitas a comunidades, a afluentes de rios, às escolas, dentre outras.

$\mathrm{Na}$ sexta questão, os docentes foram questionados sobre como avaliam as metodologias adotadas em sala de aula, e a maioria respondeu que a aceitação dos alunos no tocante a esse tipo de estrátegia é positiva e se reflete na melhor assimilação dos conhecimentos adquiridos nessas situações.

Em seguida, foram os mesmos indagados sobre as atividades realizadas fora da escola, voltadas para a temática, se realizavam esses tipos de trabalho extra-classe. Cerca de $50 \%$ respondeu que sim e $50 \%$ afirmou que não realiza atividades fora da escola. Em seguida, na oitava questão tratando dos trabalhos com projetos, $100 \%$ dos professores responderam realizar esse trabalho em suas disciplinas.

Ao responderem a nona questão que os interrogava sobre a existencia da interdisciplinaridade nas atividades com projetos, ainda segundo os professores: $80 \%$ respondeu que existe de fato a interdisciplinaridade no desenvolvimento dos projetos, e $20 \%$ disseram que não. Já na décima e última questão perguntou-se quais atitudes seriam favoráveis à construção de uma prática interdisciplinar. Destacou-se algumas respostas como: "pode-se conseguir uma efetiva prática interdisciplinar dando maior enfoque ao planejamento conjunto, onde as áreas de ensino possam estar intimamente relacionadas". "Dessa maneira cada uma com sua particularidade fariam do ensino um eixo integrador, tornando a aula um pouco mais atraente para 0 corpo discente". Pode-se verificar que ainda falta um pouco de colaboração de alguns professores para que se efetive a prática interdisciplinar na instituição, porém, já estão no meio do caminho em busca do ensino critíco e reflexivo.

Dando continuidade será discutida as respostas da equipe pedagógica e administrativa da instituição, composta por uma diretora e duas coordenadoras pedagógicas, sendo uma coordenadora do nível fundamental I e outra do fundamental II.

A questão inicial, tratava de averiguar qual concepção é dada a Educação Ambiental. Toma-se por base a resposta de uma das gestoras: "o estudo destinado a desenvolver nas pessoas conhecimentos, habilidades e 
atitudes voltadas para a preservação do meio ambiente". Em suma todas concordam e afirmaram ser a EA formadora de opiniões, que conscientizam as pessoas a mudar de atitude no que diz respeito a preservação do meio ambiente.

Como a equipe é responsável pela parte de "capacitação" dos demais agentes do ensino aprendizagem, fez-se pertinente saber na segunda questão se já foi ministrado algum curso de Educaçao Ambiental na escola para o corpo docente. A resposta foi negativa, apenas existiram algumas palestras sobre a temática, apesar desse tipo de trabalho dever ser frequente em todas as redes de ensino.

$\mathrm{Na}$ terceira questão, perguntou-se sobre a presença da Educação ambiental na construção do PPP da escola. Toda a equipe respondeu que existia a presença da temática no referido documento e ainda ressalta a importância, no entanto ao se analisar o referido documento constatou-se o contrário.

Seguindo a linha de raciocínio questionou-se como era feita a inclusão da EA na escola e as respostas foram unânimes. Disseram ser um tema transversal e por isso está presente no planejamento de todas as disciplinas, porém, após as analises feitas, podemos perceber que o fato só se concretiza na aplicação de projetos temáticos não no cotidiano. Notamos ainda, que a escola tem um discurso inclusivo no que diz respeito à EA na instituição, mas nem todos os trabalhos voltados para a temática ambiental envolvem todas as turmas.

$\mathrm{Na}$ quinta questão, a equipe pedagógica foi indagada sobre a existência de projetos relacionados a EA. As respostas foram positivas, segundo a mesma, existem projetos que estão em vigor há alguns anos como, por exemplo, o projeto: "Com Vida e a Horta Escolar", que englobam e mobilizam toda a escola. $\mathrm{Na}$ questão posterior, seguindo o raciocínio da anterior, perguntou-se se os projetos traziam benefícios a escola. As educadoras enfatizaram que os projetos tem provocado algumas mudanças comportamentais positivas nos alunos, novos comportamentos com relação a preservação do ambiente, o uso de materiais recicláveis para construção de artigos de decoração que enfeitam a escola e o uso das hortaliças na preparação da merenda escolar.

Em seguida, as gestoras foram perguntadas sobre quais problemas ambientais são causadores de maiores danos ao meio ambiente nos dias atuais. As respostas foram: a falta de saneamento básico e uma política de arboriação, poluição de afluentes e lixões a céu aberto. Em seguinda, na questão oito, interrogamos sobre qual é o destino final dado aos resíduos sólidos produzidos na escola e a equipe pedagógica afirmou que sua grande maioria é levada pela coleta do município e apenas as garrafas pets são reaproveitadas. 
Já na questão nove, perguntamos sobre a existência de trabalho com reciclagem na escola, e se era efetivo e a resposta foi que o trabalho com reciclagem é feito com alguns materiais alternativos dentre eles as garrafas pets. Segundo os gestores, também realizaram oficinas com os alunos, e na realização dos projetos o trabalho com materias reaproveitavéis é bastante explorado.

$\mathrm{Na}$ última questão, interrogamos sobre a origem dos produtos da merenda escolar. Duas das entrevistadas disseram não saber a origem, e a terceira disse que "deve vir aqui da região", sendo assim, as respostas dessa questão não foram esclarecedoras.

\section{Conclusão}

O presente trabalho teve como finalidade diagnosticar a EA na Escola Municipal Professor Severino Bezerra, além de observar e analisar o grau de afinidade das turmas de $8^{\circ} \mathrm{e} 9^{\circ}$ anos com a temática.

Neste âmbito, pode-se concluir que a escola em questão tem buscado formas concretas de incluir a EA em sua grade curricular, bem como no cotidiano (vivência) escolar do aluno. Para isso, se faz necessário a participação mais concreta e efetiva de todos os sujeitos envolvidos no processo ensino-aprendizagem, dentre eles o alunado, os educadores e a parte administrativa da instituição.

Haja vista que, para que isso aconteça as instituições em geral devem ter consciência da necessidade de incluir a Educação Ambiental como tema transversal e interdisciplinar. O que não acontece com todas as disciplinas da grade curricular da instituição. Segundo respostas dos próprios professores e alunos só as disciplinas que tem relação mais estreita com a temática, como Ciências e Geografia contemplam ao longo do ano letivo a temática ambiental.

Já as demais disciplinas, o máximo que fazem é se envolver em algum projeto, esfacelando ainda mais 0 ensino, pois cada um contribui individualmente com sua área de conhecimento e não conseguem fazer a ponte, não se envolvem em planejar aulas de campo, extraclasse ou metodologias parecidas.

Percebe-se que os alunos se mostraram bastante receptivos com relação a temática, e demonstraram total interesse em desenvolver as tarefas a eles direcionadas. As aulas de campo fazem com que o ensino seja mais atraente, com isso facilita a assimilação dos conhecimentos. De maneira geral, se almeja que cada educador contribua para que se firme a escola como espaço de conhecimento e cultura, que não seja somente espaço de consumo, onde apenas se busca e se reproduzem informações. 
Uma das maneiras de diminuir os "problemas ambientais", segundo o que foi visto, seria buscar meios de construir elementos para a elaboração de um conjunto de indicadores que mensurem, a um só tempo e de forma integradora, o bem estar individual, com o coletivo e em especial com o meio ambiente, ou seja, buscar um equilíbrio entre essas três esferas.

Através da parceria de professores e equipe pedagógica incumbidos da missão de ao menos tocar os alunos no que diz respeito aos problemas socioambientais, decorrentes em sua maioria das ações antrópicas ao longo dos anos, possam sensibilizá-los e induzí-los a construirem novos valores e adotarem hábitos mais sustentáveis. Para o bem das novas gerações, que seus filhos e netos tenham chance de desfrutar e se maravilhar com as grandes belezas naturais que ainda dispõe a região.

Portanto, pretendeu-se com esse trabalho expor um pouco da contribuição das bases teóricas para efetivação de uma EA Crítica, fazendo-se perceber o quão é longo o caminho a percorrer pelas instituições de ensino que visam ter êxito nesse processo. Fazendo notar a necessidade de políticas públicas mais eficazes, pois através dessa parceria a escola terá mais possibilidades de fazer um trabalho produtivo.

\section{Referências}

BRASIL. Secretaria de Educação Fundamental. Parâmetros Curriculares Nacionais: Apresentação dos Temas Transversais. Secretaria de Educação Fundamental. Brasília: MEC/SEF, 2001. 436p. (terceiro e quarto ciclos).

BRASIL. Secretaria de Educação Fundamental. Parâmetros curriculares nacionais: introdução aos parâmetros curriculares nacionais. Secretaria de Educação Fundamental. Brasília: MEC/SEF, 2001. 174 p. (terceiro e quarto ciclos).

CARVALHO, I.C.M. Rumo a uma ética ambiental: novas reciprocidades. In:CARVALHO, .C.M. Educação Ambiental: a formação do sujeito ecológico. 4. ed. São Paulo: Cortez, 2008.

CARSON, R. Primavera silenciosa. 2. ed. Título do original norteamericano: SILENT SPRING. São Paulo: Comp. Melhoramentos, 1962. Disponível

em:

$<$ http://bemtevi.riseup.net/ agroecologia/Primavera silenciosa-

Rachel Carson.pdf>. Acesso em: 20 ago. 2011.

DIAS, G. F. A situação da Educação Ambiental no Brasil é Fractal. In: Oficina de trabalho realizada em março de 2000. Panorama da educação ambiental no ensino fundamental/ Secretaria de Educação Fundamental. Brasília: MEC; SEF, 2011. p. $149 . \quad$ Disponível em: <http://www.crmariocovas.sp.gov.br/pdf/pol/panorama educacao.pdf >. acesso em: 08 ago 2011. 
FENSTERSEIFER, T. Direitos fundamentais e proteção do ambiente: a dimensão ecológica da dignidade humana no marco jurídicoconstitucional do estado sócio ambiental de direito. Porto Alegre: livraria do advogado, 2008.

GUIMARÃES, M. A formação de educadores ambientais. Campinas, SP: Papirus, 2004. (Coleção Papirus Educação).

GUIMARÃES, M. Educação Ambiental Crítica. In: LAYRARGUES, P.P. (coord.). identidades da educação ambiental brasileira/Ministério do Meio Ambiente. Diretoria de Educação Ambiental; Brasília: Ministério do Meio Ambiente, $2004 . \quad$ p. $156 . \quad$ Disponível em: <http://www.usp.br/pure/scc/upload/identidades\%20da\%20educa\%E7\%E30 \%20ambiental\%20br.pdf> Acesso em: 08 ago. 2011.

GUTIÉRREZ, F.; PRADO, C. Ecopedagogia e cidadania planetária. 4. ed. São Paulo: Instituto Paulo Freire, 2008. 128p. (Guia da escola cidadã; 3).

JAMIESON, D. Ética e meio ambiente. São Paulo: Editora Senac, 2010.

LOUREIRO, F.B.; LAYRARGUES, P.P.; CASTRO, R.S. Educação Ambiental: repensando o espaço da cidadania. 4. ed. São Paulo: Cortez, 2008.

MARCATTO, C. Educação ambiental: conceitos e princípios. Belo Horizonte: FEAM, 2002.

PENA-VEJA, A.Para um paradigma transdisciplinar? Pensar o contexto e o complexo. In: NASCIMENTO, E.P.; PENA-VEJA, A.; SILVEIRA, M.A. (org). Interdisciplinaridade e Universidade no século XXI. Braspilia: Ed. Abaré, 2008, p. 17-28.

SOBRAL, H.R. Globalização e Meio Ambiente. In: DOWBOR, L.; IANNI, O.; RESENDE, P. Desafios da Globalização. Petrópolis-RJ: Vozes, 1997.

SATO, M. Educação Ambiental. São Paulo: Intertox-Rima, 2004.

SILVA, A.S. Educação Ambiental: aspectos teórico-conceituais, legais e metodológicos. In: Oficina de trabalho realizada em março de 2000. Educação em Destaque, Juiz de Fora, V.1, n. 2, p. 45-61, 2. sem. 2008. 